\title{
APROPRIAÇÃO DO ESPAÇO ESCOLAR URBANO POR CRIANÇAS DE
}

\author{
ÁREA RURAL \\ Leticia Michele Stencell \\ Ana Paula Soares da Silva ${ }^{2}$
}

\begin{abstract}
RESUMO
O fechamento de escolas e a oferta de vagas para crianças de área rural na cidade compõem a política educacional adotada por municípios brasileiros. 0 objetivo do estudo foi compreender a apropriação dos espaços escolares urbanos por crianças de área rural entre 6 e 8 anos de idade. A pesquisa pautou-se pelo conceito de apropriação do espaço da Psicologia Ambiental e pelo referencial teórico-metodológico vigotskiano. Participaram da pesquisa cinco crianças matriculadas no $1^{\circ}$ e $2^{\circ}$ ano do Ensino Fundamental de uma escola que recebe crianças de área rural. Os instrumentos utilizados foram: rodas de conversa sobre os espaços da escola; desenhos; fotografias e conversas individuais sobre elas. Pôde-se apreender que elementos do rural, como plantas e pequenos animais, fizeram-se presentes no processo de apropriação do espaço e que a brincadeira e a imaginação, mesmo com impedimentos do espaço físico ou social, apareceram como fundamentais no uso do espaço.
\end{abstract}

Palavras-chave: Criança. Escola urbana. Rural.

\section{APPROPRIATION OF URBAN SCHOOL SPACE BY RURAL CHILDREN}

\begin{abstract}
The closure of schools and the provision of places for children from rural areas in the urban center is the educational policy that was adopted by Brazilian municipalities. The aim of the study was to understand the appropriation of urban school spaces by rural children between 6 and 8 years of age. The research was guided by the concept of appropriation of the space of Environmental Psychology and the vigotskian theoretical-methodological references. Five children in the 1st and 2nd year of an elementary school that receives children from rural areas were the

\footnotetext{
1 Mestranda em Psicologia pela FFCLRP-USP; aluna do Programa de Pós-graduação em Psicologia no Laboratório de Psicologia Socioambiental e Práticas Educativas; Bolsista da CAPES, $n^{\circ}$ 88887474474/2020-00. Orcid iD: https://orcid.org/0000-0002-7948-5893. E-mail: leticia.m.stencel@gmail.com

2 Pós-doutora em Psicologia e Professora Associada da FFCLRP-USP no Programa de Pósgraduação em Psicologia; coordenadora do Laboratório de Psicologia Socioambiental e Práticas Educativas. Orcid iD: https://orcid.org/0000-0002-0212-2402. E-mail: apsoares.silva@usp.br
} 
participants. The instruments used were: conversation circles about school spaces; drawings; photographs and individual conversations about them. It was possible to apprehend that rural elements, such as plants and small animals, were present in the process of appropriation of space and that games and imagination, even with physical or social space impediments, appeared as fundamental in facilitating the use of space.

Keywords: Children. Urban school. Rural.

\section{APROPIACIÓN DEL ESPACIO ESCOLAR URBANO POR NINÕS DE ZONAS RURALES}

\section{RESÚMEN}

El cierre de escuelas y la provisión de plazas para niños de las zonas rurales en el centro urbano componen la política educativa adoptada por los municipios brasileños. El objetivo del estudio fue comprender la apropiación de los espacios escolares urbanos por niños rurales entre 6 y 8 años. La investigación fue realizada con el concepto de apropiación del espacio de la Psicología Ambiental y con el marco teórico-metodológico vigotskiano. Participaron cinco niños matriculados en $1^{\circ}$ y $2^{\circ}$ año de una escuela primaria que recibe niños de zonas rurales. Los instrumentos utilizados fueron: círculos de conversación sobre espacios escolares; dibujos; fotografías y conversaciones individuales sobre ellos. Se pudo aprehender que elementos rurales, como plantas y pequeños animales, estaban presentes en el proceso de apropiación del espacio y que el juego y la imaginación, incluso con impedimentos físicos o sociales del espacio, aparecían como fundamentales para facilitar el uso del espacio.

Palabras clave: Niños. Escuela Urbana. Rural.

\section{INTRODUÇÃO}

O fechamento das escolas rurais é uma prática adotada por muitos municípios brasileiros nas últimas décadas. Esta situação ocorre em contraposição à determinação no Estatuto da Criança e do Adolescente (BRASIL, 1990), que estabelece a oferta de vagas públicas para as crianças e adolescentes próximas às suas residências (artigo 53, inciso V). Essa posição aparece também em resoluções do Conselho Nacional de Educação (BRASIL, 2002; BRASIL, 2008), que legislam sobre a oferta da educação do campo. Segundo Bezerra Neto e Santos (2016), mais de 37 mil escolas rurais foram fechadas nos quinze anos anteriores à publicação. Este fato expõe a ausência de investimento educacional brasileiro nos territórios rurais e a substituição da oferta de vagas em áreas rurais pela política de transporte das crianças para as escolas citadinas (FERREIRA; BRANDÃO, 2017). 
Estudos (BARBOSA; GEHLEN; FERNANDES, 2012; CARVALHO; LEITE; NASCIMENTO, 2017; SANTOS; SILVA, 2016) apontam que as crianças de área rural, quando estudam na cidade, são submetidas a situações desgastantes, como o transporte precário, trajeto cansativo e deteriorado. Além do transporte, também aspectos pedagógicos incidem nas experiências educacionais das crianças. Para Cavalcante (2015), ocorre uma descontextualização das práticas pedagógicas, presentes na cultura escolar e na própria formação docente, o que impede o rompimento de barreiras simbólicas que se interpõem na relação da escola com as crianças dos territórios rurais.

As vivências desse processo podem impactar a construção das identidades pessoais e sociais das crianças, uma vez que os aspectos negligenciados nas propostas e práticas pedagógicas empobrecem as potencialidades educativas e os recursos mediadores do processo ensinoaprendizagem. Soma-se a isso a dificuldade de professores em incorporar práticas que considerem a origem das crianças (CAVALCANTE, 2015). De acordo com [informação oculta para não identificação dos autores], a experiência cotidiana das crianças rurais possui especificidades socioculturais, como a relação com o ambiente natural e cultivos diversos, que se revelam durante atividades e interações na casa e na escola e que nem sempre são tomadas como parte do processo pedagógico.

Outro elemento presente nessa problemática é o imaginário negativo acerca das populações rurais, construído em um processo histórico de valorização do urbano e de sua vinculação ao ideário de progresso; ao rural, por outro lado, foram destinados significados atrelados a uma condição de atraso (FILHO; SILVA, 2018). No contexto escolar, Paiva (2008) evidencia o processo de humilhação das crianças nas escolas citadinas por meio de relatos de situações em que adaptam a linguagem e a vestimenta ao contexto urbano para não serem ridicularizadas. Oliveira (2015) concluiu que o currículo da escola urbana não abordava a diversidade entre seus alunos. A desconsideração do lugar de vida das crianças de territórios rurais caminha com concepções e práticas que negam o conhecimento da 
população, produzem seu silenciamento e se materializam nos tempos e espaços da escola sem considerar suas especificidades.

O estudo tem como objetivo compreender a apropriação dos espaços escolares urbanos por crianças do $1^{\circ}$ e $2^{\circ}$ ano do Ensino Fundamental, provenientes de área rural do distrito de uma cidade no interior de São Paulo. A partir do conceito de apropriação do espaço da Psicologia Ambiental e da teoria vigotskiana, buscou-se identificar os sentidos e significados que emergem nas apresentações que as crianças fazem dos espaços na escola e de seus usos. Investigar como as crianças de área rural se apropriam do espaço permite encontrar indícios sobre o acolhimento da diversidade sociocultural na escola, assim como visibilizar as avaliações que as crianças fazem enquanto sujeitos desse espaço.

\section{Apropriação do espaço e escola: um olhar ambiental}

Desde a geografia de Milton Santos (2006), o espaço pode ser entendido como conjunto indissociável de sistemas de ações e sistemas de objetos, ou seja, é produto e produtor de um modo de interação entre homem e natureza, datado historicamente e resultado das necessidades sociais criadas ao longo do tempo. Nessa perspectiva, o espaço se reorganiza pelos movimentos que a sociedade inicia e reinicia, sendo síntese da dinâmica social, coconstitutiva entre o mundo físico e a sociedade que o renova; nesse processo, os objetos do espaço têm seus significados modificados ao longo da história e pelas gerações. Seus significados não são neutros, pois são pautados pelos jogos de forças sociais promovidos pelos conhecimentos diversos que os indivíduos produzem (SANTOS, 2006).

É nesse movimento que os sujeitos se apropriam do espaço, modificando-o e sendo por ele modificado, tornando-o parte de suas vivências. Para Pol e Valera (1994) e Vidal e Pol (2005), isso pode ser potencializado quando o meio dispõe de elementos da cultura do indivíduo, pois há mais chances de ele identificar-se com o espaço e nele expressar-se. Dessa forma, o indivíduo consegue agir sobre os espaços onde habita, com abertura para transformá-los, imprimir significações próprias, personalizadas, 
resultando num movimento de dupla modificação: do mundo e de si mesmo. Quando as interações socioespaciais são significativas, aumentam as possibilidades de construções cognitivas e afetivas acerca do espaço, o enraizamento e o apego ao lugar e a construção de vínculos, identidade e sentimentos de proteção e segurança (VIDAL et al., 2013).

Pode-se pensar que o fato de a escola estruturar-se para receber a diversidade, de modo a incorporar aspectos da vida das crianças, constitui-se em elemento mediador que afeta seu processo de identificação com o espaço e com seu próprio meio de origem. Interessa assim compreender como a criança das áreas rurais interage com o espaço estrangeiro, dele se apropria e o transforma simbolicamente em lugar para si.

Segundo Valera (1997), no processo de apropriação do espaço, a superação da lógica posta por ideologias presentes nos projetos de construção de um espaço e nas rotinas de seu uso depende de como funcionam as relações de poder, os modos de organização, a estruturação social, assim como a história do lugar. Os espaços nos quais as crianças de áreas rurais estudam portam referências construídas por outros sujeitos, em diferentes tempos históricos. A arquitetura escolar imprime uma forma para as atividades e as vivências sensoriais, carrega uma história de concepções e expectativas do processo educativo e, neste sentido, possui dimensão formadora ou pedagógica (ESCOLANO, 2001).

Para além desses aspectos, quando se considera a problemática das crianças de área rural em escolas urbanas, deve-se relembrar que as relações entre o projeto de educação e urbanização são intrínsecas e deixam suas marcas nas construções escolares. Para Escolano (2001), vertentes arquitetônicas modernistas fomentaram o papel estratégico das instituições educacionais na consolidação do urbanismo racional. Por sua vez, na atualidade, Faria (2012) reivindica que seja superada a lógica racional da segregação, confinamento e controle, edificada na origem das instituições escolares, e que atribui peso fundamental ao espaço da sala de aula e à relação professor-aluno. 
Desde outra perspectiva, Raimann e Raimann (2008) destacam o projeto de educação como bem econômico, com diferenciados investimentos. Quanto maior a proximidade das escolas com os grandes centros urbanos, maiores são as construções e melhores as oportunidades para as crianças. As escolas das periferias contam com menor dispêndio econômico e poucas oportunidades destinadas a uma camada da população sujeita às precárias condições de vida, impedindo novas reconfigurações sociais.

Pensar a relação das crianças de áreas rurais e o espaço escolar urbano significa confrontar diferentes lógicas de governo dos corpos e tempos das crianças por meio do espaço educativo. Entretanto, desde uma perspectiva relacional, a apropriação do espaço escolar pelas crianças deve ser considerada parte de um processo que articula as concepções passadas, os usos presentes e as (im)possibilidades de recriação do espaço na transformação em um lugar para si.

\section{MÉTODO}

Participaram cinco crianças do $1^{\circ}$ e $2^{\circ}$ anos do Ensino Fundamental (EF) de área rural que estudavam em escola localizada no centro urbano de um distrito: dois meninos (Junior e Sato) e três meninas (Bia, Isabela e Manuela), entre 6 e 8 anos de idade. A escolha dos $1^{\circ}$ e $2^{\circ}$ anos justificou-se pelo fato de as crianças estarem no momento inicial de entrada no EF, um momento supostamente mais rico do processo de apropriação do espaço, dada a novidade da experiência. Apenas Isabela citou a experiência em pré-escola urbana, anterior à entrada no EF.

Os participantes da pesquisa vivem em fazendas, sítios e estâncias e seus familiares são trabalhadores assalariados, desempenhando funções como caseiro de fazenda, agricultor, cuidador de animais e zelador de estruturas físicas em locais usados para eventos em área rural. No caso de quatro participantes, algum membro da família trabalhava no comércio do distrito para complementar a renda, em especial a mãe ou irmã(o) das crianças. 
A pesquisa foi aprovada pelo Comitê de Ética em Pesquisa com Humanos [informação oculta para não identificação dos autores]. Os nomes das crianças são fictícios e foram escolhidos por elas após demonstrarem interesse de participar da pesquisa mediante seu assentimento e consentimento de seus responsáveis.

\section{Local}

A pesquisa foi realizada em uma escola do distrito de Bonfim Paulista situado no município de Ribeirão Preto. A escola atendia aproximadamente 580 alunos. Destes, 265 eram do Ensino Fundamental I, sendo 51 alunos no $1^{\circ}$ e $2^{\circ}$ ano, contabilizando seis crianças de área rural.

Nesta área, o rural é basicamente constituído por fazenda de cana de açúcar no modelo do agronegócio e, portanto, de trabalhadores rurais assalariados, sendo que a minoria sobrevive como agricultor familiar. Contudo, a agricultura não é a atividade mais rentável para o município, que possui como principal atividade econômica a prestação de serviços e comércio.

O distrito conta com população de aproximadamente 12 mil moradores (IBGE, 2012) que vivem do comércio local ou de trabalhos assalariados e, nas últimas décadas, sofre modificações em seu território pela expansão de condomínios fechados em seu entorno. Essa mudança aumentou o custo de vida e encareceu o solo do distrito.

\section{Procedimentos}

As crianças participantes estudavam em uma das quatro escolas que atendem crianças de área rural do município. Após o contato com as escolas e a concordância em participar da pesquisa de uma delas, foi feito contato com as professoras do $1^{\circ}$ e $2^{\circ}$ ano do Ensino Fundamental para verificar quais crianças eram de área rural. As seis crianças indicadas foram chamadas para conversar sobre os objetivos da pesquisa em linguagem acessível e verificar a motivação para participação. Também levaram o Termo de Consentimento Livre e Esclarecido (TCLE) para seus responsáveis. 
Adicionalmente, foi feito contato telefônico com os familiares por meio dos registros da escola. Apenas uma criança não pôde participar porque a pesquisa ocorreria após o turno escolar, no intervalo em que esperavam o ônibus, e ela não fazia parte do grupo de crianças que usava o transporte escolar.

O material empírico foi construído a partir de anotações em diário de campo e de produções das crianças. Os procedimentos foram: (i) observação livre do recreio registrada em diário de campo, realizada durante quatro dias, com vistas a apreender como as crianças da escola utilizavam $\bigcirc$ espaço naquele momento; (ii) rodas de conversas audiogravadas com as crianças participantes, para identificar os significados e os sentidos sobre os espaços da escola. As rodas de conversa foram disparadas por meio de perguntas e desenhos propostos para complementar as informações sobre o lugar de moradia das crianças, o que faziam no contraturno escolar, como iam para a escola, de que mais gostavam e de que não gostavam na escola, com quem compartilhavam os espaços escolares e quais os tempos de uso; (iii) fotografias dos espaços preferidos registradas pelas crianças participantes, sem quantidade estabelecida; (iv) conversa individual audiogravada disparada pelas fotografias com vistas a apreender os usos e sentidos atribuídos a cada lugar fotografado, o tempo de utilização dos espaços preferidos, suas percepções sobre o lugar, as emoções e os sentimentos despertados.

Os múltiplos instrumentos foram escolhidos para aprofundar 0 conteúdo dos usos e os sentidos do espaço escolar por meio de linguagens diversas e viabilizar suas expressões, permitindo autonomia para expor suas vivências como protagonistas de seu espaço (CRUZ, 2006). Além disso, os procedimentos respeitaram a ação corporal das crianças e ajudaram a captar suas relações na dinâmica com o espaço, seja quando foram convidadas a andar pelos espaços e explicitar as vivências, seja quando foram convidadas a dialogar para produzir significados. Todos os procedimentos foram realizados na ordem supracitada, acontecendo uma vez por semana e após a aula, em um período de 30 minutos disponibilizados 
pela direção da escola, no pátio escolar. As rodas de conversa foram feitas com duas (Isabela e Manuela) e três crianças (Bia, Junior e Sato), em dias diferentes, com distribuição feita pelas crianças de acordo com a intimidade que havia entre elas. Havia uma máquina fotográfica e as crianças se organizavam para utilizá-la acompanhadas pela pesquisadora.

\section{Análise de dados}

A análise dos dados foi feita a partir da leitura do material e da identificação de pontos em comum e divergentes. Vigotski (2018) propõe a busca por unidades de análise que permitam a apreensão da totalidade da experiência da criança. Identificar os significados e sentidos atribuídos pela criança é uma forma de compreender sua vivência, conceito que, para Vigotski (2018), expressa a unidade meio e pessoa.

A identificação desses significados exige do(a) pesquisador(a) olhar atento e ampliado sobre o material coletado, pois o conhecimento é uma construção da realidade observada. É preciso que o(a) pesquisador(a) consiga ir além da manifestação imediata do fenômeno, superando a descrição baseada na correlação entre causas. Deve apreender o movimento do objeto a ser estudado, tendo postura crítica que reúna a análise dos mínimos detalhes, de suas contradições, explorando a criatividade na síntese de vários conhecimentos e na explicação da interação entre eles (NETTO, 2009).

Portanto, o conhecimento é um processo que procura entender um fenômeno em sua dialética, no qual o(a) pesquisador(a) formula questões sobre ele (SOUZA FILHO, 2005). Todas as formas de expressão são igualmente importantes, desde que mobilizadas por procedimentos que permitem que a criança crie uma representação da sua própria subjetividade e consiga se aproximar da significação do outro pesquisador(a) (BARROS, 2012).

O material produzido com cada criança foi lido várias vezes e analisado separadamente e, posteriormente, foram buscadas as similitudes para a construção das categorias, que sintetizam e viabilizam a elucidação dos processos emergentes da relação das crianças com o espaço escolar. 
Os significados das formas de apropriação do espaço escolar foram apreendidos em suas tensões, compondo as seguintes categorias: (i) espaços internos $X$ externos; (ii) espaços projetados pelos adultos $X$ espaços ressignificados pelas crianças; (iii) controle $X$ liberdade.

$\mathrm{Na}$ exposição dos resultados, foram escolhidos os materiais das crianças que representavam melhor o conjunto da produção relativa a cada categoria.

\section{RESULTADOS}

O quadro a seguir apresenta compilação dos materiais gráficos e visuais produzidos pelas crianças para retratar os espaços escolares, incluindo aqueles de que mais gostam de estar e o que representam para elas.

QUADRO 1 - Caracterização das fotografias do espaço escolar

\begin{tabular}{|c|c|c|}
\hline Criança & Número de fotografias & Espaços registrados \\
\hline Bia & 7 & $\begin{array}{c}\text { Mata atrás da quadra (3), rampas do } \\
\text { prédio (3), muro do pátio (1) }\end{array}$ \\
\hline Isabela & 9 & $\begin{array}{c}\text { Corredor (1) e porta da sala de aula } \\
\text { fechada (2), exposição de trabalhos } \\
\text { infantis (1), canteiro (1), rampa (2) e } \\
\text { pátio (2) }\end{array}$ \\
\hline Junior & 6 & $\begin{array}{c}\text { Rampas (3), pátio (1), canteiro (1) e } \\
\text { escada da quadra (1) }\end{array}$ \\
\hline Manuela & 5 & Rampas (3) e pátio (2) \\
\hline Sato & 7 & $\begin{array}{c}\text { Rampas (2), pátio (1), portas da sala de } \\
\text { aula (1), do banheiro (1) e da sala de } \\
\text { esportes (1) e mata atrás da quadra (1) }\end{array}$ \\
\hline
\end{tabular}

Fonte: As Autoras

A rampa foi fotografada por todas as crianças e considerada como local preferido, juntamente com outros elementos que compõem o pátio, pois são espaços em que passam parte significativa do período escolar e, em geral, são atividades dinâmicas, que envolvem as brincadeiras. Apesar de alguns elementos da escola mostrarem-se mais 
importantes para algumas crianças do que para outras, foi possível perceber que a maioria destacava elementos naturais, como a mata atrás da quadra, o canteiro, a área verde do pátio, as árvores e os sapos que apareciam ali e o muro que as separava de uma pequena criação de galinhas. É na relação entre essas imagens e as explicações das crianças sobre seus usos que as tensões dos significados do espaço emergiram.

\section{Espaços internos $X$ espaços externos}

O pátio é o palco das brincadeiras durante o horário do recreio. Este foi citado como o lugar "mais legal da escola" (Roda de conversa, 2018, p. 56), em detrimento de outros, principalmente o espaço interno da sala de aula. A sala de aula apareceu associada ao que podemos identificar como um espaço cansativo e de contenção do corpo pela mobília tradicional. Algumas crianças relataram que estudar era "chato" (fala do Sato, 2018, p. 58) e que o pátio tornava a instituição mais agradável.

O pátio da escola é um espaço retangular dividido em cinco partes: a parte central, que dá acesso aos corredores de entrada e saída; as partes laterais, que são cobertas com telhas; e, entre estas, há dois espaços sem cobertura, com canteiros gramados. Mesmo com permanência diária curta (vinte minutos diários de recreio) nesse espaço, as crianças o mencionavam várias vezes, associando-o a inúmeras atividades e, principalmente, às possibilidades de interação social que nele ocorrem: "É do pátio onde que eu corro aqui, com bola também e a gente fica brincando, toma lanche" (fala do Junior, 2018, p. 114).

É no pátio que se localiza a quadra onde os meninos e as meninas se dividem para brincar. Entre as brincadeiras que vivenciam nesse espaço, estão o jogo de futebol e a improvisação, como jogo de tênis de mesa e uso de embalagens recicláveis de refrigerantes. Já as meninas relataram preferir brincar no pátio quando havia alguns móveis empilhados, pois era possivel fazer deles seus esconderijos e interagir com animais escondidos, como o sapo que aparecia nos dias chuvosos. Contudo, reclamavam da perda do esconderijo em virtude de a gestão escolar ter 
retirado os móveis antigos, inutilizados devido à infestação por roedores e anfíbios.

Os espaços externos aparecem em oposição aos espaços internos, tanto has falas das crianças como nas fotografias, enquanto espaços que permitem situações de grande mobilidade corporal e de criação de brincadeiras. O desejo de ocupação dos espaços internos também aparece associado àquelas atividades mais vinculadas à movimentação, criação e imaginação, exemplificado pelo diálogo a seguir:

E vocês gostam de ficar na sala de aula? (Pesquisadora).

Eu gosto. Quando tem aula de arte eu gosto (Sato).

Quando tem educação física (Bia)

O que que tem na sala da aula? (Pesquisadora).

Tem nossos cadernos, nossa, nossos brinquedos e só. Só isso, eu tenho que pensar mais (Sato).

E é muito grande a sala? (Pesquisadora).

É pequena, mas dá pra se esconde. Tira tudo as mesas (Sato).

A sala de aula, quando cumpre sua função vinculada a uma pedagogia mais tradicional, aparece como o lugar de que menos gostam:

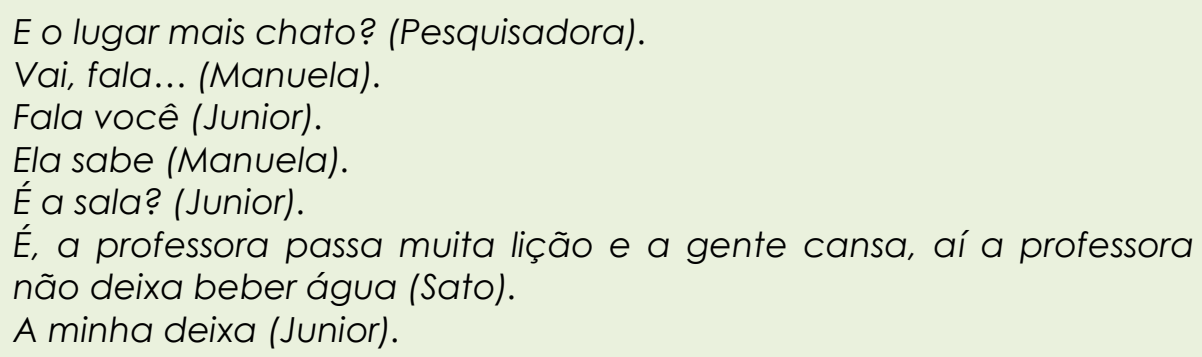

Algumas crianças tiraram fotografias de portas, pois as salas de aula e a sala de materiais de esportes estavam fechadas e só poderiam ser frequentadas com a presença de um adulto. As crianças manifestaram a vontade de entrar e fotografar o espaço e de apropriar-se das salas fechadas de forma lúdica. Os momentos nos espaços internos que elas valorizaram relacionavam-se à diversão, à brincadeira, à produção de desenhos e à contação de histórias.

Assim, a dinâmica entre os espaços internos e externos se deu mediada pelas (im)possibilidades de recriações, imaginação e movimentos. 


\section{Espaços projetados pelos adultos $X$ espaços ressignificados pelas crianças}

Espaços e objetos na escola, projetados e arranjados pelos adultos, adquirem significados próprios do grupo de crianças, que reconstroem seus usos originais. Um desses espaços são as rampas presentes na escola. Todas as crianças relataram gostar muito dos espaços inclinados, que faziam parte da arquitetura da escola devido às condições geográficas do terreno; estes apareceram nos desenhos e, principalmente, nas fotografias. A rampa na escola, construída e projetada por adultos, cumpre função estrutural em um terreno íngreme para escoamento de água. No processo de apropriação do espaço da escola pelas crianças, a rampa torna-se um brinquedo, como apontado nas rodas de conversa e nas fotografias:

\footnotetext{
A rampa? Mas porque você tirou foto da rampa? (Pesquisadora). Porque é legal! (Manuela).

É legal? [...] e como faz para brincar na rampa? (Pesquisadora). É só você escorregar (Manuela).

Em pé [...] e não suja pelo menos a bunda (Junior).

A rampa... a rampa grande que é essa aqui e a rampa pequena que onde que a gente mais brinca que é mais seguro (Bia).
}

Além das preferências de em qual rampa brincar, as crianças criavam estratégias para utilizá-las de forma a produzir diversão, como escorregador e, principalmente, ponto de interação com outras crianças.

Além da rampa, a caixa de mangueira contra incêndio foi transformada em esconderijo de objetos; o remanescente de árvores ao fundo da escola foi transformado em floresta encantada e palco da criação de suas histórias.

O canteiro de terra também apareceu em alguns relatos como um bom lugar da escola. Ele é utilizado pelas crianças porque possui algumas pedras, onde costumam pular e pegar pedaços de madeira, além de interagir com pequenos animais, como insetos. Bia destacou sua preferência por ele e até Ihe atribui um nome: "o canteiro de espinhos" - um espaço de terra, cercado por concreto. Para a nomeação, entram em cena alguns cactos plantados ali. Ela imagina uma floresta onde brinca ser princesa em 
seus próprios contos de fada. Outra área é denominada de "floresta", que se localiza próxima à quadra de esportes; ele é imaginado pela menina como lugar secreto e mágico, distante dos adultos.

Na tensão entre espaços projetados e ressignificados, aparecem elementos como plantas, árvores e a terra, que aproximam esse cenário daquele presente nas histórias de contos de fadas, compostas por narrativas de matas fechadas e densas, cheias de mistério. Também é no diálogo entre esses elementos dos contos de fada e os cantos da escola que aparecem aspectos das vivências no ambiente de moradia rural.

\section{Controle X liberdade}

Se a imaginação recria espaços já projetados, são os usos fora do olhar do adulto que se pronunciam como instantes de liberdade no cotidiano regrado e controlado da escola. Nos momentos das atividades de desenho, foi possível reconhecer uma dinâmica de apropriação baseada na vivência, partilhada e cúmplice entre os pares, de seus interesses para além das permissões dos adultos:

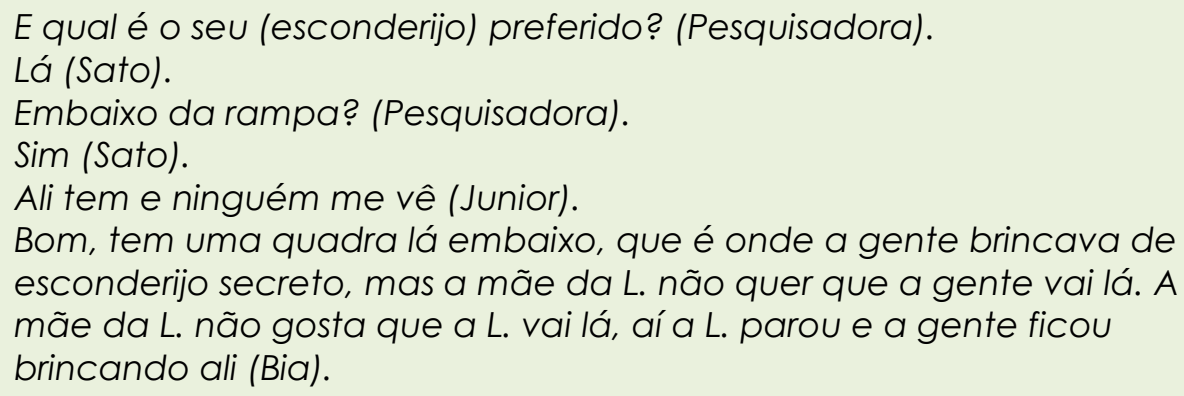
esconderijo secreto, mas a mãe da $L$. não quer que a gente vai lá. $A$ mãe da L. não gosta que a L. vai lá, aí a L. parou e a gente ficou brincando ali (Bia).

A mediação controlada dos usos dos espaços aparece ora internalizada como a voz da mãe, ora materializada nas regras, nos tempos e nas interações que restringem o acesso aos locais desejados. A própria atividade de fotografar os espaços preferidos evidenciou esse movimento. Nem todas as crianças tiraram as fotos de todos os espaços que queriam:

Mas você tirou da quadra? (Pesquisadora).

(Não). Porque, o portão estava aberto, mas eu fiquei com medo de me trancarem lá. Aí eu não fui (Junior). 
E quando que vocês vão lá? (Pesquisadora).

Bem, só quando tem educação física. (Bia).

O portão fica fechado? (Pesquisadora).

Fica. (Isabela).

Ah, porque (se) não tem educação física... e eu não posso sair da sala. Tem que pedir, senão a tia fica brava e eu vou para a diretoria. E a diretora grita que berra. Mais do que um leão furioso (Bia).

Bia só vai até a "floresta encantada" nas aulas de Educação Física ou quando consegue driblar a atenção da professora para sair da quadra e brincar de faz-de-conta entre as árvores. Junior e Sato vão a seus esconderijos na hora do intervalo, único horário destinado ao uso do pátio. Manuela e Isabela escorregam na rampa na hora do recreio, porque, nos demais momentos, o pátio é apenas um lugar de passagem. Em horários não relacionados a estas atividades, a circulação fica impossibilitada.

A própria estrutura do prédio foi projetada para limitar alguns de seus usos. Na escola, existiam grades que dividiam os espaços e impediam a circulação livre. Para ir à quadra, era necessário passar por duas grades que separavam o pátio e as salas de aula do local. As salas de aula e de material esportivo também ficavam fechadas. Muitas fotografias ficaram restritas às portas e, quando perguntado para as crianças o porquê destes espaços trancados, a resposta era para que elas não entrassem e não fizessem "bagunça". As regras passaram a ser internalizadas, também como formas de descrições de si mesmas e de seus comportamentos.

Uma vez que a circulação não era livre e que as chaves não estavam sob o controle das crianças, as possibilidades de apropriação se davam nas resistências, nas ações que emergiam a partir das lacunas desse tipo de controle exercido pelos adultos. O portão que dava acesso ao jardim da escola e ficava perto da quadra em que os meninos jogavam futebol permanecia fechado. As meninas apenas conseguiam ver as galinhas que ali habitavam através de buracos no muro.

\section{Discussão}

A partir do conjunto do material e diante do objetivo de compreender a apropriação dos espaços escolares urbanos por crianças do $1^{\circ}$ e $2^{\circ}$ ano do 
Ensino Fundamental, provenientes de área rural de um distrito no interior de São Paulo, pôde-se apreender que a brincadeira e a imaginação apareceram como fundamentais na facilitação do mesmo, por mais que houvesse impedimentos concretos de sua utilização.

A identificação, a simbolização e a personalização do espaço (POL; VALERA, 1994; POL, 1996) mostraram-se imbricados nos usos concretos e nas possibilidades imaginativas das crianças. À medida que as crianças falavam, fotografavam e desenhavam seus espaços, suas memórias eram mobilizadas indicando suas vivências. Consequentemente, pode-se perceber o grau de importância que os lugares da escola adquiririam para elas, seus significados e as transformações por elas propostas, de acordo com o que percebiam e simbolizavam neles e sobre eles (BOMFIM; DELABRIDA; FERREIRA, 2018).

Foi também essa mobilização das memórias e vivências que produziu relações mediadas por aspectos da condição de moradora em área rural. Árvores, canteiros com mato e plantas espalhadas pelo pátio, galinhas, insetos e sapos atuavam na criação de cenários para a produção de histórias e imaginação. Estes elementos apareceram nas interações das crianças com os espaços da escola como instrumentos de resgate de lembranças (GONÇALVES; MARTINS, 2014). O ambiente em que os sujeitos habitam, a configuração afetiva dos lugares e as relações sociais passadas são primordiais para conectar os ambientes de onde vieram e os ambientes onde vivem (GREEN; KALVAITIS; WORSTER, 2015). E isso constrói a base para um sentimento de identificação e pertencimento, promovendo um processo dialético em que, ao mesmo tempo em que o sujeito se modifica, o espaço também muda (POL, 1996).

Assim, junto com algumas características da escola, dois processos primordiais atuam na mediação na apropriação do espaço pelas crianças: a brincadeira e a imaginação. Apesar das avaliações negativas das crianças sobre aspetos da escola, os momentos de brincadeira revelaram-se os mais prazerosos e faziam valer a pena estar lá, pois desfrutavam de maior liberdade para criar e serem ativas no coletivo de criança e entre seus pares. Não havia brinquedos no pátio, mas a liberdade, 
a acessibilidade e alguns aspectos físicos permitiam a criação de locais próprios, individuais ou compartilhados, já que o próprio espaço comportava, contraditoriamente, também elementos não necessariamente diretivos a certas práticas (FRANCK; STEVENS, 2007). A preferência por espaços e áreas livres, em especial o pátio, aparece em conformidade com - que discute Faria (2011), associada à noção de liberdade, em contraposição à sala de aula. Para a autora, "mais do que diversa, a natureza das atividades no pátio e na sala de aula são de certa forma opostas" (FARIA, 2011, p.35).

Graças à maior liberdade no período do recreio e das aulas de Educação Física, as crianças exploravam os ambientes e criavam brincadeiras que Ihes faziam sentido. Era principalmente por meio dessas brincadeiras que as crianças se apropriavam dos espaços, descobrindo e criando esconderijos, avaliando (im)possibilidades dos lugares em termos de trânsito de pessoas e de amplitude do espaço. A importância do pátio e as outras áreas livres no sistema de relações da criança, segundo Azevedo et al. (2011), sinaliza para a função simbólica que essas áreas exercem na apropriação que a criança faz do espaço escolar. Nesse processo, a ludicidade é central.

Essas gratificações e boas vivências levam o indivíduo a perceber-se pertencido, sentindo-se particularmente relacionado a uma comunidade e ao espaço (GIULIANI, 2003), assim como sentir-se seguro para compartilhar suas experiências. Essa segurança foi percebida quando as crianças recriavam os usos originais dos espaços e objetos. A significação do ambiente pareceu estruturada também pela emoção imbricada na atividade da criança no espaço. A resposta afetiva das crianças foi a de valorização dos lugares na escola, tornando-os carregados de significado e simbologias (CORRALIZA; BERENGUER, 2010).

A rampa foi o principal objeto que apareceu com outro significado. A priori, seria um detalhe arquitetônico projetado por adultos, talvez, com outro tipo de uso inimaginável; mas o que se verificou foi a apropriação inventiva e lúdica pelas crianças. Houve, nessa prática, 
reconstrução simbólica a partir do momento em que passou a ser habitada por um coletivo de crianças que deu nova utilidade à configuração daquele objeto (VALERA, 1997).

Além de objetos, os espaços adquiriram significados distintos daqueles usuais e construídos formalmente em que as crianças aproximavam vivências da escola e de seu lugar de moradia, como o Canteiro de Espinhos e a Floresta Encantada. Ao mesmo tempo, estes lugares inspiram histórias de contos de fadas, indicando sua importância na ligação de diversas vivências das crianças em distintos tempos e espaços materiais ou simbólicos, passados ou presentes, reais ou imaginados.

Essa vivência ocorre mediada por relações interpessoais e por momentos de partilha e companheirismo entre as crianças; assim, constroem suas relações e expressam quem são situadas no espaço.

Contudo, apesar de as crianças demonstrarem bom conhecimento dos espaços da escola e deles se apropriarem, a liberdade de criação tem seus limites e a instituição restringe o seu acesso e os seus tempos de permanência. Sepúlveda (2009) fala da disciplinarização das crianças, controle da linguagem e imposição de regras para o uso dos espaços promovidos pela educação, que negam os corpos das crianças e suas vivências íntimas e pessoais. Para o autor, e conforme nossa pesquisa, os espaços estão inscritos no indivíduo. Nesse sentido, é preciso que a educação permita que as crianças se coloquem no espaço de modo que sua vivência tenha sua voz e desejo, que não seja o tempo todo controlada pelo adulto e que suas experiências sejam potencializadas e incentivadas.

\section{CONSIDERAÇÕES FINAIS}

A pesquisa convida a pensar sobre o processo de apropriação do espaço escolar pelas crianças de áreas rurais em escolas urbanas e, assim, a repensar os espaços-tempos permitidos ou cerceados às crianças, a fim de que o espaço da escola faça emergir sujeitos expressivos e potencialize as suas capacidades criativas, articuladas à vivência e ao contexto de vida. A apropriação do espaço é apenas um meio de apreender como as vivências 
das crianças ocorrem nas escolas, mas pode contribuir para indicar a qualidade com que estas ocorrem e como o espaço contribui (ou não) para o desenvolvimento das crianças.

Isso requer, não eliminar regras e tempos controlados pelos adultos, mas deslocar a centralidade do processo educativo de espaços internos para externos, de controle excessivo dos adultos para possibilidades organizativas partilhadas com as crianças. Esse processo permitiria romper com a lógica do ensino-aprendizado aprisionado na sala de aula desde a arquitetura escolar do início do século XX (FARIA, 2012) e compreender possibilidades de construção do conhecimento mais comprometidas com a expressividade dos sujeitos presentes naqueles espaços. Está aí a potência de aprendizados integrais no interior da própria escola. Se essa é uma provocação para a escola de forma geral, ela o é ainda mais especialmente para crianças provenientes de área rural, cuja sociabilidade, paisagem, vivência temporal e espacial possuem particularidades que medeiam as singularidades e as subjetividades das crianças.

Os resultados, apesar das pistas que levantam para a apreensão do processo de apropriação do espaço escolar, sugerem a necessidade de estudo mais amplo, com a abordagem de múltiplos métodos para aprofundar o processo de apropriação do espaço pelas categorias construídas neste estudo.

Por fim, ressalta-se que esta pesquisa, assim como o referencial teóricometodológico expressa, é um recorte temporal e espacial de um fenômeno complexo e amplo e que foi apreendido por olhares que não são neutros e imutáveis. É preciso que a relação das crianças nas séries iniciais com os espaços escolares seja estudada por outros olhares e perspectivas.

\section{Agradecimentos}

Esta pesquisa de Iniciação Científica recebeu financiamento do processo $\mathrm{n}^{\circ}$ 2016/05709-6. Fundação de Amparo à Pesquisa do Estado de São Paulo (FAPESP). 


\section{REFERÊNCIAS}

AZEVEDO, G. A. N. et al. Qualidade do lugar da paisagem no pátio escolar: fundamentos e conceitos. In: Azevedo, G. A. N.; RHEINGANTZ, P. A.; TÂNGARI, V. R. (Orgs.). O lugar do pátio escolar no sistema de espaços livres: uso, forma e apropriação. Rio de Janeiro: UFRJ/FAU/PROARQ, 2011. p. 57-76.

BARBOSA, M. C. S.; GEHLEN, I.; FERNANDES, S. B. A oferta e a demanda de Educação Infantil no campo: um estudo a partir de dados primários. In: BARBOSA, M. C. S. (Coord.). Oferta e demanda da educação infantil no campo. Porto Alegre: Evangraf, 2012. p. 71-106.

BARROS, J. P. P. Constituição de "sentidos" e "subjetividades": aproximações entre Vygotsky e Bakhtin. Estudos Contemporâneos da Subjetividade, [S. I.], V. 2. $\quad$ p. 133-146, 2012. Disponível em: http://www.periodicoshumanas.uff.br/ecos/article/view/724. Acesso em: 20 jul. 2018.

BEZERRA NETO, L.; SANTOS, F. R. Neoconservadorismo, movimentos sociais e educação no campo no Brasil. Crítica Educativa, [S. I.], v. 2, n. 1, p. 52-65, 2016. DOI: 10.22476/revcted.v2i1.77. Disponível em: https://www.criticaeducativa.ufscar.br/index.php/criticaeducativa/article/vi ew/77. Acesso em: 5 maio 2018.

BOMFIM; Z. A. C.; DELABRIDA, Z. N. C.; FERREIRA, K. P. M. Emoções e afetividade ambiental. In: CAVALCANTE, G.; ELALI, G. A. (Orgs.). Psicologia ambiental: Conceitos para a leitura da relação pessoa-ambiente. Petrópolis: Vozes, 2018. p. 60-74.

BRASIL. Lei no 8.069, de 13 de julho de 1990. Dispõe sobre o Estatuto da Criança e do Adolescente e dá outras providências. Diário Oficial [da] República Federativa do Brasil: Brasília, DF, 16 jul. 1990. Disponível em: http://www.planalto.gov.br/ccivil_03/leis/l8069.htm. Acesso em: 16 dez. 2018.

BRASIL, Conselho Nacional de Educação. Resolução CNE/CEB n. 01, de 03 de abril de 2002. Institui diretrizes Operacionais para a Educação Básica nas Escolas do Campo. Brasília: Diário Oficial da União, 03 abr. 2002. Disponível em:

http://portal.mec.gov.br/index.php?option=com_docman\&view=download \&alias=13800-rceb001-02-pdf\&category_slug=agosto-2013-pdf\&ltemid=30192. Acesso em: 23 de janeiro de 2018.

BRASIL, Conselho Nacional de Educação. Resolução CNE/CEB n. 02, de 28 de abril de 2008. Estabelece diretrizes complementares, normas e princípios para - desenvolvimento de políticas públicas de atendimento da Educação Básica do Campo. Brasília: Diário Oficial da União, 28 abr. 2008. Disponível em:

http://portal.mec.gov.br/index.php?option=com_docman\&view=download 
\&alias=11841-rceb002-08-pdf\&category_slug=outubro-2012pdf\&ltemid=30192. Acesso em: 23 jan. 2018.

CARVALHO, W. L.; LEITE, P. S.; NASCIMENTO, H. P. O processo evolutivo do transporte escolar rural brasileiro no modo rodoviário. Revista Eletrônica de Engenharia Civil, [S. I.], v. 13, n. 1, p. 118-127, 2017. DOl: https://doi.org/10.5216/reec.v13i1.42400. Disponível em: https://www.revistas.ufg.br/reec/article/view/42400. Acesso em: 04 maio 2018.

CAVALCANTE, G. C. Campo e cidade: interações entre saberes e práticas socioeducativas no interior de uma escola. Trabalho publicado nos Anais do XII Congresso Nacional de Educação (EDUCERE), III Seminário de Representações Sociais, Subjetividade e Educação (SIRSSE), IX Encontro Nacional sobre Atendimento Escolar Hospitalar. Curitiba: PUCPR, 2015, p. $18146-18161$. https://educere.pucpr.br/dados/2015/apresentacao.html. Acesso em: 29 jul. 2018.

CORRALIZA, J. A.; BERENGUER, J. Emoción y ambiente. In: ARAGONÉS, J. I.; AMÉRIGO, M. A. (Coords.). Psicología ambiental. 3. ed. Madri: Pirámide, 2010. p. 59-75.

CRUZ, S. H. V. Ouvindo crianças: considerações sobre o desejo de captar a perspectiva da criança acerca da sua experiência educativa. In: DELACOURS-LINS, S.; CRUZ, S. H. V. (Orgs.). Linguagens, literatura e escola. Fortaleza: Editora UFC, 2006. p. 1-18.

ESCOLANO, A. Arquitetura como programa, espaço-escola e currículo. In: ESCOLANO, A.; FRAGO, A. V. Currículo, espaço e subjetividade: a arquitetura como programa. Tradução A. VEIGA-NETO. 2. ed. Rio de Janeiro: DP\&A, 2001. p. 21-55.

FARIA, A. B. G. O pátio escolar como ter[ritório] [de paisagem] entre a escola e a cidade. In: AZEVEDO, G. A. N.; RHEINGANTZ, P. A.; TÂNGARI, V. R. (Orgs.). O lugar do pátio escolar no sistema de espaços livres: uso, forma e apropriação. Rio de Janeiro: UFRJ/FAU/PROARQ, 2011 . p. 35-44.

FARIA, A. B. G. Por outras referências no diálogo arquitetura e educação: na pesquisa, no ensino e na produção de espaços educativos escolares e urbanos. Em aberto, [S. I.], v. 25, n. 88, P. 99-111, 2012. DOI: 10.24109/21766673.emaberto.25i88.

em: http://rbep.inep.gov.br/ojs3/index.php/emaberto/article/view/3088. Acesso em: 25 mar. 2019.

FERREIRA, F. J.; BRANDÃO, E. C. Fechamento de escolas do campo no Brasil e o transporte escolar entre 1990 e 2010: na contramão da educação do 
campo. Imagens da Educação, [S. I.], v. 7, n. 2, p. 76-86, 2017. DOI: http://doi.org/10.4025/imagenseduc.v7i2.36910. Disponível em: https://periodicos.uem.br/ojs/index.php/ImagensEduc/article/view/36910. Acesso em: 5 mar. 2018.

FILHO, I. D. C.; SILVA, C. Reflexões sobre a educação do campo: revisitando a história do Brasil. Revista Educação Popular, [S. I.], v. 16, n. 3, p. 67-83, 2018. DOI: https://doi.org/10.14393/REP-v16n32017-art05. Disponível em: http://www.seer.ufu.br/index.php/reveducpop/article/view/38835. Acesso em: 27 maio 2019.

FRANCK, K. A.; STEVENS, Q. Loose spaces: Possibility and Diversity in Urban Life. Londres: Routledge, 2007.

GIULIANI, M. V. Theory of attachment and place attachment. In: Bonnes, M.; LEE, T.; BONAIUTO, M. (Eds.). Psychological theories for environmental issues. Aldershot: Ashgate, 2003. p. 137-170.

GONÇALVES, T. M.; MARTINS, R. J. Apropriação do espaço na pré-escola segundo a Psicologia Ambiental. Psicologia \& Sociedade, [S. I.], v. 26, n. 3, p. 622-631, 2014. DOl: https://doi.org/10.1590/\$0102-71822014000300011. Disponível em: https://www.scielo.br/pdf/psoc/v26n3/allv26n3.pdf. Acesso em: 20 jan. 2018.

GREEN, C.; KALVAITIS; D.; WORSTER, A. Recontextualizing psychosocial development in young children: a model of environmental identity development. Environmental Education Research, [S. I.], v. 22, n. 7, p. 10251048, 2015. DOI: 10.1080/13504622.2015.1072136. Disponível em: https://www.tandfonline.com/doi/full/10.1080/13504622.2015.1072136?.casa_t oken=rs|4FtqH02QAAAAA\%3A90Pn55Uq92Zk88e9qb2pzQy7sWLII U4MViBUtTPzE 4Siu-7dcmiOlQNuRdLshHGMaXRSLaMhMdS. Acesso em: 25 jun. 2019.

INSTITUTO BRASILEIRO DE GEOGRAFIA E ESTATÍSTICA (IBGE). Censo Brasileiro de 2010. Rio de Janeiro: IBGE, 2012.

NETTO, J. P. Introdução ao método da teoria social. In: CFESS (Org.). Serviço Social - Direitos sociais e competências profissionais. Brasília: CFESS / ABEPSS, 2009. p. 667-700.

OLIVEIRA, C. D. S. O aluno do campo na escola urbana e sua diversidade cultural. 2015. 58f. TCC (Especialista em Educação e Diversidade) Universidade Federal do Pampa, Rio Grande do Sul/RS, 2015. Disponível em: http://dspace.unipampa.edu.br:8080/bitstream/riv/660/1/O\%20ALUNO\%20D O\%20CAMPO\%20NA\%20ESCOLA\%20URBANA.pdf. Acesso em: 27 out. 2019.

PAIVA, D. I. Crianças de zona rural, alunos de escola urbana. 2008. $85 f$ Dissertação (Mestre em Linguística Aplicada) - Universidade Estadual de 
Campinas, Campinas/SP, 2008. Disponível em: http://repositorio.unicamp.br/jspui/handle/REPOSIP/269538. Acesso em: 20 jan. 2018.

POL, E. La apropiación del espacio. In: L. IÑIGUEZ, L; POL, E. (Comps.). Cognición, representación y apropiación del espacio. Barcelona: Publicacions de la Universitat de Barcelona, 1996. p. 45-62.

POL, E.; VALERA, S. El concepto de identidad social urbana: una aproximación entre la Psicología Social y la Psicología Ambiental. Anuario de Psicología, [S. I.], n. 62, p. 5-24, 1994. Disponível em: https://dialnet.unirioja.es/servlet/articulo? codigo=2946898. Acesso em: 5 maio 2018.

RAIMANN, E. G.; RAIMANN, C. Arquitetura e espaço escolar na produção de subjetividades. Itinerarius Reflectionis, [S. I.], v. 4, n. 2, p. 1-14, 2008. DOI: 10.5216/rir.v2i5.527. Disponível em: https://www.revistas.ufg.br/rir/article/view/20418. Acesso em: 05 jun. 2018.

SANTOS, F. R.; SILVA, A. M. Fechamento das escolas rurais e transporte escolar no município de Morrinhos/GO. Interfaces da Educação, [S. I.], v. 7, n. 21, p. 23-42, 2016. DOI: 10.26514/inter.v7i21.1222. Disponível em: https://periodicosonline.vems.br/index.php/interfaces/article/view/1222. Acesso em: 30 jun. 2018.

SANTOS, M. O espaço geográfico, um híbrido. In: SANTOS, M. A natureza do espaço: técnica e tempo, razão e emoção. 4. ed. São Paulo: Edusp, 2006. p. 57-66.

SEPÚLVEDA, U. Vidas y corpos despojados del lugar: la espacialidad propuesta por el mundo escolar. In: PEREIRA, M. G. (Ed.). La espesura del lugar: reflexiones sobre el espacio en el mundo educativo. Santiago: Universidad Academia de Humanismo Cristiano, 2009. p. 85-101.

SOUZA FILHO, R. Apontamentos sobre o materialismo dialético. Libertas, [S. I.], v. 3, n. 1 e n. 2, p. 115-130, 2005.

VALERA, S. Public space and social identity. In: REMESAR, A. (Ed.). Urban regeneration: a challenge for public art. Barcelona: Publicacions de la Universitat de Barcelona, 1997. p. 77-85.

VIDAL, T. et al. Place attachment, place identity, sense of community, and local civic participation in an urban renewal context. Estudios de Psicología, [S. I.], v. 34, n. 3, p. 275-286, 2013. DOI: $10.1174 / 021093913808295172$. Disponível em: https://www.tandfonline.com/doi/abs/10.1174/021093913808295172. Acesso em: 08 jul. 2018. 
VIDAL, T.; POL, E. La apropiación del espacio: una propuesta teórica para comprender la vinculación entre las personas y los lugares. Anuario de Psicología, [S. I.], v. 36, n. 3, p. 281-297, 2005. Disponível em: https://revistes.ub.edu/index.php/Anuario-psicologia/article/view/8593. Acesso em: 03 mar. 2018.

VIGOTSKI, L. S. Quarta aula. O problema do meio na pedologia. In: Z. PRESTES, Z.; TUNES, E. (Orgs.). Sete aulas de L.S. Vigotski sobre os fundamentos da pedologia. Tradução de Z. Prestes, E. Tunes e C. C. G. Santana. Rio de Janeiro: E-papers, 2018. p. 73-91.

Recebido em: 24 de dezembro de 2021.

Aprovado em: 29 de novembro de 2021. Publicado em: 20 de dezembro de 2021. 